\title{
Retention and interference in the beetle Tenebrio Molitor
}

\section{LARRY C. WALRATH, University of California, Santa Barbara, Calif. 93106}

Beetles (Tenebrio molitor) were trained in a T-maze, maintained in a temperature-reduced environment for 1,2 , 3 , or 4 days, and retrained in the maze. Ss demonstrated appreciable savings except those experiencing a 2-day delay. These animals showed impaired performance in comparison with original performance. The performance curve is interpreted as an interference function rather than as a retention function.

Alloway \& Routtenberg (1967) reported that relearning performance in a T-maze is a function of intersession interval in Tenebrio molitor. Beetles trained to criterion in the maze experienced delays of $1,2,3,4$, or 5 days before returning to the maze. Under normal conditions, beetles showed a typical forgetting function. Beetles cooled to $1.7^{\circ} \mathrm{C}$ during the delay, however, showed somewhat increasing retention after $1,3,4$, or 5 days, with a sizable decrement following an intersession interval of 2 days. Beetles not cooled failed to show a depression in performance at 2 days. On reversal learning, a delay of 2 days produced learning analogous to original learning, while with longer or shorter intersession intervals, the original training interfered with reversal acquisition. The purpose of the present study was to replicate, in part, the Alloway and Routtenberg study. Since the usual conceptualizations of memory do not seem to account for the effect, and since there did not appear to be any significant motivational changes as a result of the cooling procedure, it was felt that a replication would be important.

\section{SUBJECTS}

Flour beetles, Tenebrio molitor, were procured from colonies of the University of California at Santa Barbara and maintained in a free-breeding colony on a cereal mixture of cornmeal, oatmeal, and Kellogg's Special $\mathrm{K}$ in a wood chip and potato medium. At least $24 \mathrm{~h}$ prior to the experiment, 16 Ss were transferred to individual styrofoam living cups containing the cereal mixture.

Fig. 1. Number of errors during relearning for $\mathrm{Ss}$ who experienced various delays between original learning and relearning.

\section{APPARATUS}

A Plexiglas T-maze with a fine-grain sandpaper floor was used throughout the experiment. The initial runway was $5.3 \mathrm{~cm}$ long, and each arm was $5.7 \mathrm{~cm}$ long. The alleys measured $0.8 \mathrm{~cm}$ wide and $1.3 \mathrm{~cm}$ deep. A Plexiglas lid covered the entire maze, and Plexiglas slides could be inserted into each runway. Heat and light were provided by a $25-\mathrm{W}$ incandescent bulb, $7.5 \mathrm{~cm}$ above the choice point. The temperature in the maze was approximately $28^{\circ} \mathrm{C}$. The goalboxes were styrofoam cups similar to the living cups, with entries cut at the bottom. The positive goal, containing the cereal mixture from the home cup, had a styrofoam cover that blocked the heat and light. The negative cup was open to the light and had a sandpaper floor.

\section{PROCEDURE}

The Ss were assigned randomly to one of four experimental groups. Initial preference was determined by running each $\mathrm{S}$ three times to empty goalboxes. The nonpreferred side was designated as positive for all subsequent training. All Ss received original training under an identical paradigm. Positive reinforcement consisted of a minimum of $2 \mathrm{~min}$ in the positive goalbox. Negative reinforcement consisted of a minimum of $1 \mathrm{~min}$ in the negative goalbox. Ss were run to a criterion of five successive correct trials.

After attaining criterion, each $\mathrm{S}$ was returned to his home cup, which was then transferred to a refrigerator at approximately $2^{\circ} \mathrm{C}$. Ss in Experimental Group 1 remained in the refrigerator for 1 day and then received retraining. Ss in Groups 2, 3, and 4 remained in the cooled state for 2, 3, or 4 days, respectively. Each $\mathrm{S}$ was maintained at room temperature for
30 to $60 \mathrm{~min}$ prior to relearning. Relearning followed the same paradigm as original learning.

The Ss were handled with a modified tongue depressor to minimize variations in handling. The same tongue depressor was used as a goalbox door to prevent reentry into the maze. Following two consecutive errors, a plastic block was inserted into the negative arm of the maze, forcing $S$ to turn to the positive arm. Forced trials did not constitute correct trials for the purpose of establishing criterion performance. RESULTS AND DISCUSSION

Original learning was analyzed for trials to criterion and number of errors. Although some inequality appears between groups, $F$ tests revealed no significant differences $(F=1.28,1.34$, for trials and errors, respectively, $\mathrm{df}=3 / 12, \mathrm{p}>.25$ ).

During relearning, $\mathrm{Ss}$ in the 2-day delay group performed more poorly than any of the other three groups (Fig. 1). F tests on nonforced trials to criterion and errors revealed a significant difference between groups $(F=5.49, d f=3 / 12, p<.05$ for trials, and $F=7.89, \mathrm{df}=3 / 12, \mathrm{p}<.01$ for errors). A planned comparison $t$ test (Hays, 1963 , p. 464) based on the one-way analysis of variance showed Group 2 to be significantly different from the other three groups $(\mathrm{p}<.001$ for both trials and errors). Each animal in Group 2 performed more poorly than any animal in Groups 1 , 3 , or 4 , i.e., there was no overlap between Group 2 scores and the other three groups combined.

Savings scores were determined by subtracting relearning scores from original learning scores. A one-way analysis of variance showed a significant difference between groups $(F=3.61,4.04$, for trials and errors, respectively, $\mathrm{df}=3 / 12$, $p<.05$ ). Planned comparisons based on the analysis showed Group 2 to be significantly different from the other three groups (Fig. 2). Groups 1 and 3 demonstrated significant savings; all animals performed better in the relearning

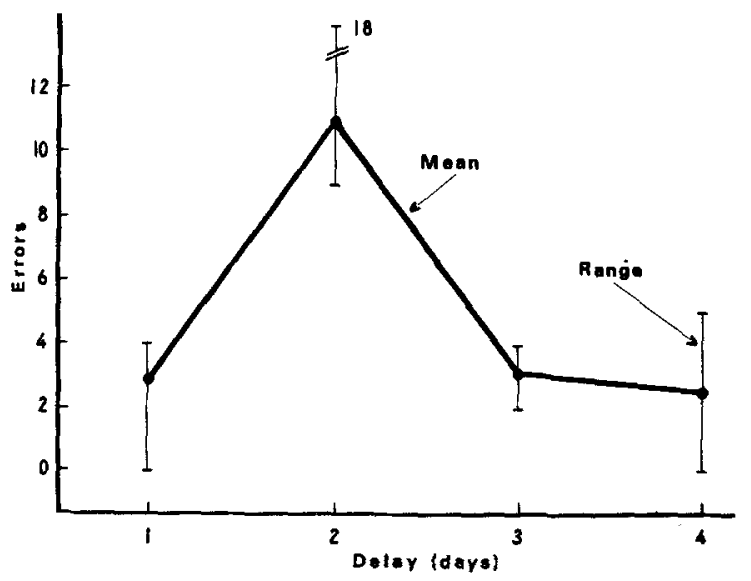


Fig. 2. Difference scores derived by subtracting the scores during relearning from those obtained during original learning. Positive scores indicate savings. Negative scores indicate interference.

task (sign test probability, $\mathrm{p}<.063$ for each group). All Ss in Group 2 not only failed to show any savings, but indicated some kind of interference. Each $S$ performed more poorly in relearning than in original learning (a priori probability $<$.063). Group 4 is less clear. Two animals in this group showed appreciable savings. The other two performed more poorly in relearning than in original learning. This may be interpreted as a chance result produced by extending the delay beyond the length of the memory function. However, an additional comparison test between Group 4 and Groups 1 and 3 indicated that the group difference was not significant. The two animals having low savings scores in this group performed well in relearning (one and four errors, within the range for Ss in Groups 1, 3, and 4, which showed some savings). The negative savings can be attributed to unusually good performance in the original learning task (zero and one errors, respectively).

The results of the present study correspond to those reported by Alloway \& Routtenberg (1967): Cooled beetles show a time-specific decrement following a delay of 2 days, but not after delays of 1 , 3 , or 4 days. In addition, the present study indicates that 2-day delay Ss, not only failed to show savings, but actually exhibited a decrement in performance compared to original learning. The previous study did not report a similar interference. Although Alloway and Routtenberg did not report a similar interference effect, they did find that reversal learning was not inhibited in the 2-day delay condition. Since 2-day animals performed well under these conditions, the interference found in relearning is not the result of lowered

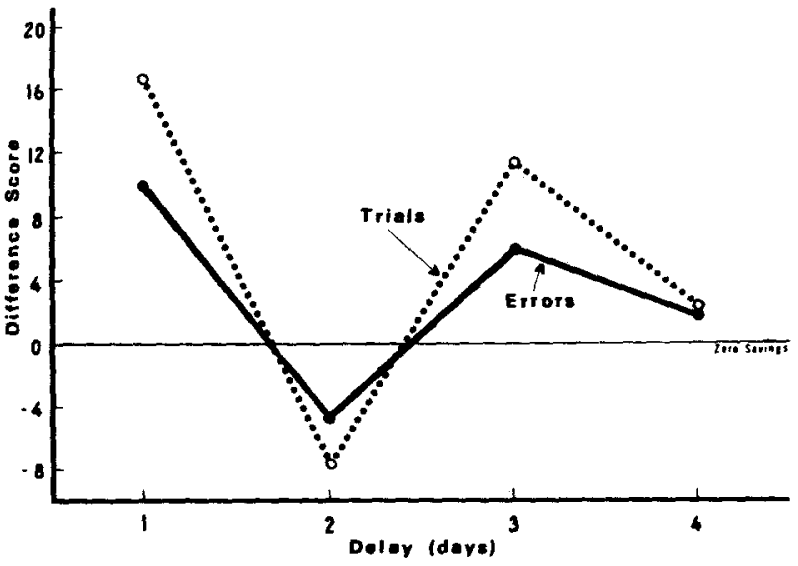

motivation or of impaired motor functioning resulting from the temperature manipulations.

It seems unlikely that current memory formulations can account for this time-specific effect. A complete failure of memory could not be spontaneously removed with the mere passage of time. Furthermore, if the effect were the result of a memory deficit, it would not be expected that relearning performance should be inferior to performance levels of original learning.

The consistent decrement in performance following a specific delay (after 2 , but not after 1, 3, or 4 , days) is reminiscent of the interference functions described originally by Kamin (1957). The interference of performance on Day 2 would appear to be the result of a temporary "disrupting" state within the animal, akin to what is commonly referred to as emotion or conditional emotional state.

If cooling slows the metabolic functioning of the beetle, the time course of the effect would be much shorter in beetles maintained at normal temperature. The form of the memory function, as determined under "normal" temperature conditions, would in that case be highly similar to the form of the effect observed in rats and labeled the "interference effect [Kamin, 1957]." A similar effect has been found in dogs (Overmier \& Seligman, 1967) and in rabbits in this laboratory.

In light of these findings, neither memory alone nor motivational level can serve as an adequate explanatory account of this time-specific performance decrement. It is suggested that the data of the present study are best described as an interference function rather than as a retention function.

\section{REFERENCES}

ALLOWAY, T, M \& ROUTTENBERG, A "Reminiscence" in the cold flour beetle (Tenebrio molitor). Science, 1967, 158, 1066-1067.

HAYS, W. L. Statistics for psychologists New York: Holt, Rinehart \& Winston, 1963.

KAMIN, L. J. The retention of an incompletely learned avoidance response. Journal of Comparative \& Physiological Psychology, $1957,50,457-460$

OVERMIER, J. B., \& SELIGMAN, M. E. P. Effects of inescapable shocks upon subsequent escape and avoidance responding. Journal of Comparative \& Physiological Psychology, $1967,63,28-33$. NOTE

1. This work was partially supported by USPHS Predoctoral Fellowship 1F1 MH-37, 778-02 PS. 